\title{
LAYANAN DAN PENGARUHNYA TERHADAP LOYALITAS NASABAH BANK SYARIAH MANDIRI KOTA PALOPO.
}

\author{
Ahmad Syarief Iskandar ${ }^{1}$ \\ Faisal Podo ${ }^{2}$ \\ ahmadsyarief@gmail.com
}

\begin{abstract}
In this study is the effect on customer loyalty to the independent Islamic bank Palopo city. In this study using field research, by examining directly the object, namely the customers of Bank Syariah Mandiri Palopo City. This research uses quantitative research. The population in this study is 3,600 customers of the Mandiri Islamic bank in Palopo city, with a sample of 100 people who were given a questionnaire. The technique used in sampling is a technique (probability sampling) of simple random sampling (random sample). The instrument used was a questionnaire with 23 statement items presented in the form of a Likert scale. The results of the research and data processing obtained are the independent variable X1 (physical form) has a significant effect on variable $\mathrm{Y}$ (Customer Loyalty) while the other four independent variables are X2 (Empaty), X3 (Reliability), X4 (Responsiveness), X5 (Guarantee). ) does not have a significant effect on variable Y (Customer Loyalty), this is proven by using the test where the physical form variable has a $t$ count of 3.847 greater than the $t$ table value of 2.627 , while the four variables have $t$ count of empathy 0.465 , reliability 0.648 , responsiveness 2.155 , and the guarantee of 0.166 is not greater than the $t$ table value of 2.627. While simultaneously the independent variables, X1 (Physical Form), X2 (Empaty), X3 (Reliability), X4 (Responsiveness) and X5 (Assurance) have a significant effect on the dependent variable Y (Customer Loyalty), this is proven by using the $f$ test. where the variables of physical form, empathy, reliability, responsiveness and assurance have f count 5,217 greater than $\mathrm{f}$ table 1.93.
\end{abstract}

Keywords: Loyalty, Customer

\section{ABSTRAK}

Dalam penelitian ini adalah pengaruhnya terhadap loyalitas nasabah terhadap bank syariah mandiri kota palopo. Dalam penelitian ini menggunakan penelitian lapangan, dengan meneliti langsung pada objek, yaitu nasabah Bank Syariah Mandiri Kota Palopo. Penelitian ini menggunakan jenis penelitian kuantitatif, populasi dalam penelitian adalah nasabah bank syariah mandiri kota palopo berjumlah 3.600 orang, dengan penarikan sampel 100 orang yang diberikan angket. Teknik yang digunakan dalam pengambilan sampel adalah teknik (probability sampling) pengambilan sampel acak sederhana (random sample). Instrumen yang digunakan adalah angket (kuosioner) dengan 23 butir pernyataan yang disajikan dalam bentuk skala likert. Hasil penelitian dan pengolahan data yang diperoleh adalah variabel bebas X1 
(Wujud fisik) berpengaruh secara signifikan terhadap variabel Y (Loyalitas Nasabah) sedangkan empat variabel bebas lainnya yaitu X2 (Empaty), X3 (Keandalan), X4 (Daya Tanggap), X5 (Jaminan) tidak berpengaruh secara signifikan terhadap variable Y (Loyalitas Nasabah), ini dibuktikan dengan menggunakan uji t dimana variabel wujud fisik mempunyai $t$ hitung 3,847 lebih besar dari nilai t tabel 2,627, sedangkan keempat variabel tersebut mempunyai t hitung empati 0,465 , keandalan 0,648 , daya tanggap 2,155, dan jaminan 0,166 tidak lebih besar dari nilai $t$ tabel 2,627. Sedangkan secara simultan variabel bebas, X1 (Wujud Fisik), X2 (Empaty), X3 (Keandalan), X4 (Daya Tanggap) dan X5 (Jaminan) berpengaruh secara signifikan terhadap variabel terikat Y (Loyalitas Nasabah), ini dibuktikan dengan menggunakan uji f dimana variabel wujud fisik, empati, keandalan, daya tanggap dan jaminan mempunyai f hitung 5,217 lebih besar dari f tabel 1.93 .

Kata Kunci: Loyalitas, Nasabah 


\section{PENDAHULUAN}

\section{A. Latar belakang Masalah}

Dunia perbankan di Indonesia dewasa ini mengalami persaingan antara bank yang semakin tajam. Persaigan dalam dunia perbankan bukan hanya berasal dari pesaing dalam negeri tetapi juga pesaing dari luar negeri, sehingga jajaran perbankan kita perlu lebih tangkas dan tanggap dalam menghadapinya. Salah satu tantangan terbesar dalam bisnis di era global seperti saat ini adalah menciptakan dan mempertahankan kepuasan serta loyalitas nasabah, karena tidak ada perusahaan yang mampu bertahan dalam jangka panjang tanpa adanya kepuasan dan loyalitas dari nasabah.

Bank syariah dikembangkan pada awalnya sebagai suatu respon dari kelompok ekonomi dan praktisi perbankan muslim yang berupaya mengakomodasi desakan dari berbagai pihak yang menginginkan tersedianya jasa transaksi keuagan yang dilaksanakan sejalan dengan nilai moral dan prinsip-prinsip syariah Islam, utamanya berkaitan dengan riba, kegiatan maisir (spekulasi) dan Gharar (ketidak jelasan). Bank Islam atau yang di sebut bank syariah adalah bank yang beroperasi dengan tidak menerapkan sistem bunga. Bank Islam atau biasa disebut dengan bank tanpa bunga adalah lembaga keuagan yang operasional dan produknya dikembangkan berdasarkan Alqur'an dan Hadist Nabi Muhammad SAW atau dengan kata lain, Bank Islam adalah lembaga keuangan yang usaha pokoknya memberikan pembiayaan dan jasa-jasa lainnya dalam lalulintas pembayaran serta peredaran uang yang pengoperasiannya di sesuaikan dengan prinsip syari'ah Islam. ${ }^{1}$

Loyalitas nasabah adalah hal yang mutlak bagi bank yang menginginkan tetap eksis dalam usahanya. Mencari nasabah baru adalah hal yang sulit, namun jauh lebih sulit adalah mempertahankan nasabah lama. Memperebutkan loyalitas nasabah merupakan kunci terpenting untuk memenangkan persaingan. Loyalitas nasabah merupakan puncak pencapaian pelaku bisnis perbankan. Nasabah yang puas dan setia tidak akan ragu untuk menjadi penyebar kabar baik yang selalu menyebarkan kebaikan mengenai produk perbankan yang dikonsumsinya. Mereka memiliki kredibilitas yang tinggi, karena tidak dibayar oleh pihak manapun untuk merekomendasikan produk atau merek perbankan tersebut. Mempertahankan nasabah yang loyal memang harus mendapatkan prioritas yang utama dari pada mendapatkan

\footnotetext{
${ }^{1}$ Hasrida Kadir, "Pengaruh Pelayanan Customer Service Terhadap Loyalitas nasabah pada Bank Syariah Mandiri Cabang Kota Palopo",skripsi, (Palopo, STAIN Palopo 2014), h.1-2
} 
nasabah baru, karena untuk merekrut atau mendapatkan nasabah baru bukanlah hal yang mudah karena akan memerlukan biaya yang banyak, maka sangatlah rugi bila perusahaan melepas nasabah yang telah loyal secara begitu saja. Untuk memenuhi kepuasan nasabah pada industri perbankan, kualitas pelayanan sagat penting bagi perusahaan untuk di kelola dengan baik agar memenuhi keinginan nasabah. Perusahaan yang gagal memenuhi kebutuhan, keinginan, selera dan proses keputusan beli konsumen akan mengalami kegagalan dalam pemasaran dan penjualannya, sehingga akan gagal juga dalam kinerja keseluruhannya.

Dalam menciptakan dan meningkatkan loyalitas nasabah, sedikitnya ada lima faktor yang di jelaskan oleh Anwar Lyndon Saputra yaitu Tangible (wujud fisik) Demensi ini merupakan aspek perusahaan yang mudah terlihat dan ditemui pelanggan, demensi ini berkaitan dengan fasilitas fisik, peralatan, teknologi dan penampilan karyawan. (2) Empathy (Empati) yaitu meliputi kemudahan dalam melakukan hubungan dengan konsumen, komunikasi yang baik, perhatian dan memahami pelanggan. (3) Reliability (keandalan) merupakan kemampuan perusahaan menyampaikan jasa yang akurat dan konsisten, dimensi ini berkaitan dengan kemampuan menyediakan pelayanan sesuai dengan disajikan, sikap simpatik, ketepatan waktu pelayanan, sistem pencatatan yang akurat. (4) Responsiveness (Daya tanggap) merupakan kemauan untuk memberikan pelayanan dan membantu pelanggan dengan segera, dimensi ini terlihat pada kecepatan pelayanan yang diberikan kepada pelanggan, keiginan karyawan untuk membantu para pelanggan. (5) Assurance ( Jaminan) adalah kompotensi, sopan santun, kredibilitas, dan keamanan membantu keyakinan pelanggan bahwa ia akan memdapatkan jasa yang diharapkan.

Atas dasar latar belakang di atas maka peneliti tertarik untuk mengangkat judul "LAYANAN DAN PENGARUHNYA TERHADAP LOYALITAS NASABAH BANK SYARIAH MANDIRI KOTA PALOPO”

\section{RUMUSAN MASALAH}

1. Adakah pengaruh, wujud fisik (Tangible), empati (Empathy), keandalan (Reliability), daya tanggap (Responsiveness) dan jaminan (Assurance) secara parsial terhadap loyalitas nasabah Bank Syariah Mandiri.

2. Adakah pengaruh wujud fisik (tangible), empaty (empathy), keandalan (Reliability), daya tanggap (Responsiveness), dan jaminan (Assurance) secara simultan terhadap loyalitas nasabah Bank Syariah Mandiri. 


\section{DEFINISI OPERASIONAL}

Skripsi ini berjudul "Layanan dan pengaruhnya terhadap loyalitas nasabah Bank Syariah Mandiri Kota Palopo" maka sangat penting untuk mendefinisikan operasional variabel agar tidak terjadi kesalahan agar memudahkan penelitian.

Proses pemenuhan kebutuhan nasabah terhadap Bank Syariah Mandiri dengan beberapa alat atau variabel. Dalam penelitian adalah sebagai berikut :

1. Wujud Fisik (tangible)

2. Empaty (empathy)

3. Keandalan (Reliability)

4. Daya Tanggap (Responsiveness)

5. Jaminan (Assurance)

Loyalitas adalah kesetian nasabah terhadap Bank Syariah Mandiri

Bank adalah badan usaha yang menghimpun dana dari masyarakat dalam bentuk simpanan dan menyalurkannya kepada masyarakat dalam bentuk kredit atau bentuk lainya dalam rangka meningkatkan taraf hidup rakyat banyak. Bank syariah merupakan bank yang kegiatanya mengacu pada hukum islam, dan dalam kegiatannya tidak membebankan bunga maupun tidak membayar bunga kepada nasabah.

Nasabah adalah orang yang menyimpan dananya di Bank Syariah Mandiri. Adapun indikatornya :

a. Wujud fisik : Nyaman, Penampilan karyawan, Fasilitas memadai.

b. Empati : Memahami kebutuhan dan kepentingan, perhatian dan kesabaran, menghargai dan mengerti keluhan nasabah.

c. Keandalan : Pelayanan maksimal, cepat dan tepat, simpatik, waktu pelayanan sesuai dengan janji.

d. Daya tanggap : Memberikan informasi lengkap, menyelesaikan keluhan dengan cepat, pelayanan cepat dan tanggap, membantu kesulitan nasabah.

e. Jaminan : Dapat menjawab pertanyaan dengan baik, sopan dan ramah, transaksi dapat dipercaya

f. Loyalitas nasabah: menggunakan jasa bank secara rutin, merekomendasikan kepada orang lain, tidak melakukan akses dengan bank lain. 


\section{TINJAUAN PUSTAKA}

\section{Pengertian Bank syariah}

"Bank syariah" adalah istilah yang dipakai di Indonesia untuk menyatakan suatu jenis bank yang dalam pelaksanaannya berdasarkan pada prinsip syariah,. Namun, "Bank Islam" (Islamic bank) adalah istilah yang digunakan secara luas dinegara lain untuk menyebutkan bank dengan prinsip syariah, disamping ada istilah lain untuk menyebut bank islam diantaranya interest free bank, lariba bank, dan shari'a bank.

\section{Kualitas pelayanan}

Kualitas merupakan suatu kondisi dinamis yang berpengaruh dengan produk, jasa, manusia, proses dan lingkungan yang memenuhi atau melebihi harapan. Defenisi kualitas pelayanan dapat diartikan sebagai upaya pemenuhan kebutuhan dan keinginan konsumen serta ketepatan penyampaiannya dalam mengimbangi harapan konsumen.

Kualitas pelayanan (service quality) dapat diketahui dengan cara membandingkan persepsi para konsumen atas pelayanan yang nyata-nyata mereka terima/ peroleh dengan pelayanan yang sesungguhnya mereka harapkan atau iginkan terhadap atribut-atribut pelayanan suatu perusahaan. Jika jasa yang diterima atau dirasakan (perceived service) sesuai dengan diharapkan, maka kualitas pelayanan dipersepsikan baik dan memuaskan, jika jasa yang diterima melampaui harapan konsumen, maka kualitas pelayanan dipersepsikan sagat baik dan berkualitas. Sebaliknya jika jasa yang terima lebih renda daripada yang diharapkan, maka kualitas pelayanan dipersepsikan buruk. ${ }^{2}$

Adapun demensi kualitas pelayanan yaitu : (1) Tangible (wujud fisik) Demensi ini merupakan aspek perusahaan yang mudah terlihat dan ditemui pelanggan, demensi ini berkaitan dengan fasilitas fisik, peralatan, teknologi dan penampilan karyawan. (2) Empathy (Empati) yaitu meliputi kemudahan dalam melakukan hubungan dengan konsumen, komunikasi yang baik, perhatian dan memahami pelanggan. (3) Reliability (keandalan) merupakan kemampuan perusahaan menyampaikan jasa yang akurat dan konsisten, dimensi ini berkaitan dengan kemampuan menyediakan pelayanan sesuai dengan disajikan, sikap simpatik, ketepatan waktu pelayanan, sistem pencatatan yang akurat. (4) Responsiveness (Daya tanggap) merupakan kemauan untuk memberikan pelayanan dan membantu pelanggan dengan segera, dimensi ini terlihat pada kecepatan pelayanan yang diberikan kepada pelanggan, keiginan karyawan untuk membantu para pelanggan. (5) Assurance ( Jaminan)

\footnotetext{
${ }^{2}$ http://skripsi-manajemen.blogspot.com/2011/02/pengertian-definisi-kualitas-pelayanan.html di akses tanggal 4 juni 215.
} 
adalah kompotensi, sopan santun, kredibilitas, dan keamanan membantu keyakinan pelanggan bahwa ia akan memdapatkan jasa yang diharapkan. Dimensi ini berkaitan dengan kemampuan karyawan untuk menanamkan kepercayaan kepada pelanggan, sikap sopan dan kemampuan karyawan dalam menjawab pertanyaan pelanggan. ${ }^{3}$

\section{Loyalitas Nasabah}

Secara bahasa loyal berarti setia, sehingga loyalitas diartikan sebagai kesetian yang timbul tanpa ada paksaan, tetapi timbul dari kesadaran sendiri. Loyalitas nasabah sebetulnya berasal dari loyalitas merek yang mencerminkan loyalitas nasabah pada merek tertentu, loyalitas nasabah sagat penting untuk di kenali pemasar dalam rangka menentukan strategi yang diperlukan untuk meraih atau memperluas dan mempertahankan pasar.

\section{Kepuasan nasabah}

Nasabah adalah pihak yang menggunakan jasa bank. ${ }^{4}$ Secara definitif, kepuasan nasabah/ konsumen dapat diterjamahkan dan dipahami berdasarkan pertanyaan-pertanyaan yang dikemukakan oleh beberapa tokoh pemasaran yaitu :

\section{Menurut Frederich Engel (1990)}

“Kepuasan konsumen merupakan evaluasi purna beli dimana alternative yang dipilih sekurang-kurangnya sama atau melampaui harapan pelanggan, sedangkan ketidakpuasan timbul apabila hasil (outcome) tidak memenuhi harapan.

Menurut Day (dalam Tse dan Wilton, 1988)

“Kepuasan atau ketidakpuasan pelanggan adalah respons pelanggan terhadap evaluasi ketidak sesuaian (disconfirmation) yang dirasakan antara harapan sebelumnya (atau norma kinerja lainnya) dan kinerja actual produk yang dirasakan setelah pemakaiannya. ${ }^{5}$

Sedangkan pengertian kepuasan konsumen menurut Kotler sebagai berikut:

Kepuasan konsumen/ nasabah adalah perasaan senang atau kecewa seseorang yang muncul setelah membandingkan antara presepsi atau kesannya terhadap kinerja (hasil) suatu produk dan harapan-harapanya. ${ }^{6}$

3 HandiIIaw, 10 Prinsip_Kepuasan Pelanggan, (Jakarta :PT. Elex Media Kompotindo, 2002), h. 57-74

${ }^{4}$ Zubairi Hasan, Undang-Undang Perbankan Syariah, (Jakarta : PT. Rajagrafindo Persada, 2009), h. 211

\footnotetext{
${ }^{5}$ Paulus Lilik Kristianto, Psikologi Pemasaran, (CAPS, Yogyakarta 2011), h.30
} 
Dari keseluruhan kegiatan yang dilakukan oleh perusahaan pada akhirnya akan bermuara pada nilai yang akan diberikan oleh pelanggan mengenai kepuasan yang dirasakan. Kepuasan merupakan tingkat perasaan dimana seseorang menyatakan hasil perbandingan atas kinerja produk (jasa) yang diterima dan diharapkan. Banyak manfaat yang diterima oleh perusahaan jika tercapainya tingkat kepuasan pelanggan yang tinggi. Tingkat kepuasan yang tinggi dapat meningkatkan loyalitas pelanggan dan mencega perputaran pelanggan, mengurangi sentivitas pelanggan terhadap harga, menguranggi biaya kegagalan pemasaran, mengguragi biaya operasi yang diakibatkan oleh meningkatnya jumla pelanggan, meningkatkan efektivitas iklan dan meningkatkan reputasi bisnis.

\section{METODE PENELITIAN}

\section{Desain Penelitian}

Desain penelitian kerangka bentuk atau rancangan. Penelitian ini bersifat pengamatan dan penganalisaan, dimana data yang diperoleh dari objek penelitian ini adalah Bank Syariah Mandiri dan subyek penelitian ini adalah Nasabah Bank Syariah Mandiri, yang diteliti dicobah untuk diamati dan dianalisa yang kemudian ditarik sebuah kesimpulan sebagai mana adanya tanpa maksud membuat kesimpulan yang berlaku untuk umum, generalisasi dan perusahaan. Sehingga metode yang dilakukan oleh peneliti saat ini adalah metode kuantitatif deskriptif. Agar penelitian lebih teratur dan terarah, maka dirancang dengan beberapa tahap yaitu : tahap identifikasi, masalah penelitian, tahap penyusunan proposal penelitian, tahap pengumpulan data penelitian, tahap analisis data penelitian, dan tahap penyusunan laporan penelitian.

Kuantitatif adalah metode penelitian yang di gunakan untuk meneliti pada populasi atau sampel tertentu. Teknik pengambilan sampel pada umumnya dilakukan secara random, pengumpulan data menggunakan instrument penelitian, analisis data bersifat kuantitatif/ statistik dengan tujuan untuk menguji hipotesis yang telah ditetapkan. ${ }^{7}$

\section{Lokasi Penelitian}

Lokasi penelitian ini penulis melaksanakan di kantor Bank Syariah Mandiri Kota Palopo.

\section{Variabel Penelitian}

\footnotetext{
${ }^{6}$ Philip Kotler, Kevin Lane Keller, Manajemen Pemasaran, (Person Education/ PT. Indeks 2006/ 2007), h. 177

${ }^{7}$ Hasrida Kadir, Op. cit, h. 26
} 
Proposal ini berjudul "Layanan dan pengaruhnya terhadap Loyalitas Nasabah Bank Mandiri Syariah" untuk memudahkan pemahaman judul di atas maka penulis membagi dua Variabel yaitu :

a. Variabel bebas (independent), yaitu wujud fisik (tangible X1), empati (empathy X2), keandalan (reliability X3), daya tanggap (responsiveness X4), dan jaminan (assurance $X 5)$.

b. Variabel terikat (dependent), yaitu Loyalitas Nasabah.

\section{Populasi dan Sampel}

Adapun populasi dalam penelitian ini adalah seluruh Nasabah Bank Syariah Mandiri Kota Palopo dari tahun 2014 sampai tahun 2015 yang berjumlah 3600 nasabah Bank Syariah Mandiri. $^{8}$

Sampel dalam penelitian ini yakni beberapa dari Nasabah Bank Syariah Mandiri Palopo yang dianggap memiliki peran sesuai dengan data yang dibutuhkan, jadi sampel yang akan diambil dengan menggunakan metode pengambilan propabilitas/ acak (Random Sampling). Dengan menggunakan rumus slovin sebagai berikut.

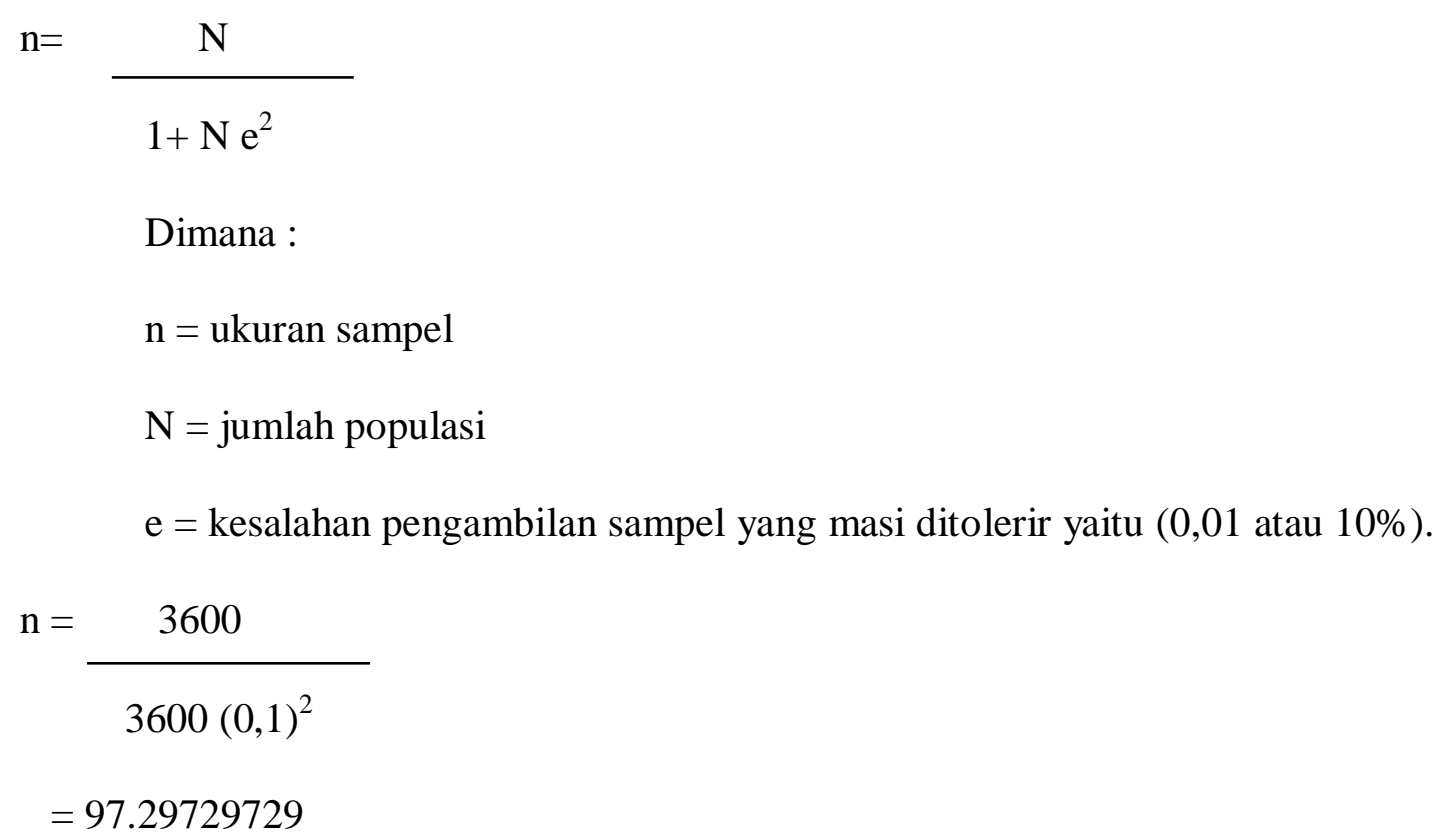

Berdasarkan perhitungan, maka diperoleh sampel sebanyak 97.29729729. dan agar penelitian ini menjadi lebih fit maka diambil 100 responden. Jadi sampel dalam penelitian ini adalah 100 responden.

\footnotetext{
${ }^{8}$ Wawancara Bapak Muh. Suhendra, Manager BSM Cabang Palopo, tanggal 28 Maret 2016.
} 


\section{Metode Pengumpulan Data}

Dalam pengumpulan data ini penulis menggunakan metode :

Metode library Research, yaitu megumpulkan dengan cara membaca buku-buku literature yang ada hubungannya dengan pembahasan.

1. Metode field Research, yaitu metode yang dilakukan untuk dilapangan dengan menggunakan cara sebagai berikut :

a. Observasi, yaitu metode pengumpulan data dengan cara mengunakan pengamatan langsung dilapangan dengan mengenal dan mengetahui objek yang akan diteliti, dalam penelitian ini penulis melakukan pengamatan langsung pada Nasabah Bank Mandiri Syariah Palopo.

b. Angket yaitu teknik atau metode pengumpulan data yang dilakukan dengan cara memberi serangkain pertanyaan atau pernyataan tertulis yang diberikan kepada responden untuk menjawabnya ${ }^{9}$ dengan tujuan mendapatkaan informasi.

c. Interview, yaitu metode pengumpulan data dengan cara mengadakan wawancara atau Tanya jawab kepada pihak-pihak yang terkait dengan informasi yang diberikan.

\section{Teknik Pengolahan dan Analisis Data}

1. Analisis Deskriptif

Analisis deskriptif adalah suatu analisis yang menguraikan tanggapan responden terhadap loyalitas nasabah sehingga membuat nasabah merasa loyal pada bank itu sendiri melalui kuensioner yang dibagikan, dengan menggunakan skala likert. Skala likert secara umum menggunakan peringkat lima angka penelitian, yaitu ; (a) Sagat Setuju, (b) Setuju, (c) Ragu-ragu, (d) Tidak Setuju, (e) Sagat Tidak Setuju. Jawaban setiap item instrument yang menggunakan skala likert mempunyai gradasi dari sangat positif sampai sangat negative yang dapat berupa kata-kata antara lain, yaitu:

Table 3.1

Gradasi Skala likert

\begin{tabular}{|c|c|c|c|c|}
\hline $\begin{array}{c}\text { Sangat Setuju } \\
\text { (SS) }\end{array}$ & $\begin{array}{c}\text { Setuju } \\
\text { (S) }\end{array}$ & $\begin{array}{c}\text { Ragu-ragu } \\
\text { (RR) }\end{array}$ & $\begin{array}{c}\text { Tidak setuju } \\
\text { (TS) }\end{array}$ & $\begin{array}{c}\text { Sangat Tidak Setuju } \\
\text { (STS) }\end{array}$ \\
\hline 5 & 4 & 3 & 2 & 1 \\
\hline
\end{tabular}

Sumber: Malhora 2005.

\footnotetext{
${ }^{9}$ Sugiyono,Metode Penelitian Kuantitatif Kualitatif dan R\&D, (Bandung, Alfabeta, 2014), h. 142
} 


\section{Uji Validitas dan Reliabilitas Instrumen}

Validitas adalah suatu ukuran yang menunjukan tingkat keterandalan atau kesahitan dari suatu alat ukur. ${ }^{10}$ Untuk menguji validitas alat ukur, terlebih dahulu dicari harga korelasi antara bagian-bagian dari alat ukur secara keseluruhan dengan cara mengkorelasikan setiap butiran alat ukur dengan skor total yang merupakan jumlah setiap skor butir.

Uji validitas untuk mengetahui tingkat kevalidan dari instrument (kuesioner) yang digunakan dalam pengumpulan data. Hal ini dilakukan untuk menguji butir-butir pernyataan yang ada di dalam kuesioner.

Dari Uji Validitas yang dilakukan dengan Pronram SPSS Versi 20 yaitu dengan melihat nilai Corrected Item Correlation. Dengan ketentuan, nilai corrected item Correlation dari masing-masing variabel > dari nilai $\mathrm{r}$ table sebesar dengan demikian dinyatakan valid dan dimasukkan ke dalam pengujian penelitian sesungguhnya.

Uji Reliabilitas suatu penelitian itu dikatakan reliabel, bila terdapat kesamaan data dalam waktu yang berbeda, instrument yang riabel belum tentu valid. Reliabilitas instrument merupakan syarat untuk pengujian validitas instrument, oleh karena itu walaupun instrumen valid umumnya pasti realibel.

\section{Uji multikolonieritas}

Bertujuan untuk menguji apakah model regresi ditemukan adanya korelasi antara variabel bebas (independent), model regresi yang baik seharusnya tidak terjadi korelasi diantara variabel bebas (tidak terjadi multikolonieritas).

4. Uji heteroskedatisitas

Bertujuan untuk menguji apaka dalam regresi variabel dari residul tidak sama untuk satu pengamatan kepengamatan yang lain, model regresi yang baik seharusnya tidak terjadi heteroskedatisitas.

5. Uji autokorelasi

Bertujuan menguji apakah dalam model regresi linier ada korelasi antara kesalahan pengganggu periode $\mathrm{t}$ dengan kesalahan pengganggu periode $\mathrm{t}-1$ (sebelumnya), model regresi yang baik adalah regresi yang bebas dari autokorelasi.

\footnotetext{
${ }^{10}$ Arikonto Suharsimi, Prosedur Penelitian Suatu Pendekatan Praktek, (Jakarta: PT. Rieneka Cipta
} 2000), h. 109. 
6. Teknik Analisis Regresi Linear Berganda

Teknik analisis regresi berganda adalah menguji variabel tak bebas dan variabel bebas dengan mengunakan rumus :

$$
\begin{array}{ll}
\mathrm{Y}=\mathrm{a}+ & \mathrm{x} 1 \mathrm{~b} 1+\mathrm{x} 2 \mathrm{~b} 2+\mathrm{x} 3 \mathrm{~b} 3+\mathrm{x} 4 \mathrm{~b} 4+\mathrm{x} 5 \mathrm{~b} 5+\mathrm{e} \\
\mathrm{Y} & =\text { Loyalitas Nasabah } \\
\mathrm{a} & =\text { Konstanta regresi } \\
\mathrm{x} 1 & =\text { Wujud fisik } \\
\mathrm{x} 2 & =\text { Empati } \\
\mathrm{x} 3 & =\text { Keandalan } \\
\mathrm{x} 4 & =\text { Daya tanggap } \\
\mathrm{x} 5 & =\text { Jaminan } \\
\mathrm{b} & =\text { koefisien regresi } \\
\mathrm{e} & =\text { Error. }
\end{array}
$$

Analisis data dilakukan dengan menggunakan sarana komputer pada program Statistical Data Analysis SPSS for WINDOWS Release 20.

\section{F. Hasil Penelitian Dan Pembahasan}

\section{Uji Validitas Dan Uji Reliabilitas}

a. Uji Validitas

Tabel 4.7 Hasil Uji Validitas X1

\begin{tabular}{|ll|l}
\hline & & item_1 \\
& Pearson Correlation & 1 \\
ritem_1 & Sig. (2-tailed) & \\
& $\mathrm{N}$ & 100 \\
& Pearson Correlation & $.347^{* *}$ \\
item_2 & Sig. (2-tailed) & .000 \\
& $\mathrm{~N}$ & 100 \\
& Pearson Correlation & $.315^{* *}$ \\
item_3 & Sig. (2-tailed) & .001 \\
& $\mathrm{~N}$ & 100 \\
& Pearson Correlation & .111 \\
item_4 & Sig. (2-tailed) & .274 \\
& $\mathrm{~N}$ & 100 \\
total_sko & Pearson Correlation & $.701^{* *}$ \\
& Sig. (2-tailed) & .000 \\
rr & $\mathrm{N}$ & 100 \\
- & & 2016
\end{tabular}

\section{Correlations}

Sumber: Data primer yang diolah. 2016

\begin{tabular}{|l|l|l|l|} 
item_2 & item_3 & item_4 & total_skor \\
$.347^{* *}$ & $.315^{* *}$ & .111 & $.701^{* *}$ \\
.000 & .001 & .274 & .000 \\
100 & 100 & 100 & 100 \\
1 & $.337^{* *}$ & $.222^{*}$ & $.698^{* *}$ \\
& .001 & .026 & .000 \\
100 & 100 & 100 & 100 \\
$.337^{* *}$ & 1 & $.295^{* *}$ & $.727^{* *}$ \\
.001 & & .003 & .000 \\
100 & 100 & 100 & 100 \\
$.222^{*}$ & $.295^{* *}$ & 1 & $.562^{* *}$ \\
.026 & .003 & & .000 \\
100 & 100 & 100 & 100 \\
$.698^{* *}$ & $.727^{* *}$ & $.562^{* *}$ & 1 \\
.000 & .000 & .000 & \\
100 & 100 & 100 & 100
\end{tabular}

${ }^{11}$ Wahid sulaiman, Analisis Regresi Menggunakan SPSS Contoh Kasus dan Pemecahannya, (Yogyakarta, Andi Offset, 2014) h. 80 
Dari tabel 4.7 di atas tampak bahwa nilai $r$ hitung item $1=0,701$, item $2=0,698$, item $3=0,727$, item $4=0,562$, sedangkan nilai $r$ tabel adalah 0,1966. Maka dapat di simpulkan bahwa semua data valid karna $\mathrm{r}$ hitung lebih besar dari $\mathrm{r}$ tabel.

Tabel 4.8 Hasil Uji Validitas X2

\begin{tabular}{|c|c|c|c|c|c|}
\hline & & Correla & & & \\
\hline & Pearson Correlation & $\begin{array}{l}\text { item_1 } \\
1\end{array}$ & $\begin{array}{l}\text { item } 2 \\
.758^{\pi \star}\end{array}$ & $\begin{array}{l}\text { item } 372^{* \pi} \\
.3\end{array}$ & $\begin{array}{l}\text { total skor } \\
.832^{\text {तx }}\end{array}$ \\
\hline item_1 & Sig. (2-tailed) & & .000 & .000 & .000 \\
\hline • & $\begin{array}{l}\mathrm{N} \\
\text { Pearson Correlation }\end{array}$ & 100 * $.758^{* *}$ & $\begin{array}{l}100 \\
1\end{array}$ & $\begin{array}{l}100 \\
.418^{* *}\end{array}$ & $\begin{array}{l}100 \\
.865^{* *}\end{array}$ \\
\hline item_2 & Sig. (2-tailed) & .000 & & .000 & .000 \\
\hline & $\begin{array}{l}\mathrm{N} \\
\text { Pearson Correlation }\end{array}$ & $\begin{array}{l}100 \\
.372^{* *}\end{array}$ & $\begin{array}{l}100 \\
.418^{* *}\end{array}$ & $\begin{array}{l}100 \\
1\end{array}$ & $\begin{array}{l}100 \\
.767^{* *}\end{array}$ \\
\hline item_3 & Sig. (2-tailed) & .000 & .000 & & .000 \\
\hline & $\begin{array}{l}\mathrm{N} \\
\text { Pearson Correlation }\end{array}$ & $\begin{array}{l}100 \\
.832^{* *}\end{array}$ & $\begin{array}{l}100 \\
.865^{* *}\end{array}$ & $\begin{array}{l}100 \\
.767^{* *}\end{array}$ & $\begin{array}{l}100 \\
1\end{array}$ \\
\hline total_skor & Sig. (2-tailed) & .000 & .000 & .000 & \\
\hline & $\mathrm{N}$ & 100 & 100 & 100 & 100 \\
\hline
\end{tabular}

Sumber: Data primer yang diolah. 2016

Dari tabel 4.8 di atas tampak bahwa nilai $r$ hitung item $1=0,832$, item $2=0,865$, item $3=0,767$, sedangkan nilai $r$ tabel adalah 0,1966. Maka dapat di simpulkan bahwa semua data valid karna $r$ hitung lebih besar dari $r$ tabel.

Tabel 4.9 Hasil Uji Validitas X3

\begin{tabular}{|ll|l}
\hline & Pearson Correlation & 1 \\
item_1 & Sig. (2-tailed) & \\
& $\mathrm{N}$ & 100 \\
& Pearson Correlation & $.614^{* *}$ \\
item_2 & Sig. (2-tailed) & .000 \\
& $\mathrm{~N}$ & 100 \\
& Pearson Correlation & .181 \\
item_3 & Sig. (2-tailed) & .072 \\
& $\mathrm{~N}$ & 100 \\
& Pearson Correlation & $.238^{*}$ \\
item_4 & Sig. (2-tailed) & .017 \\
& $\mathrm{~N}$ & 100 \\
& Pearson Correlation & $.704^{* *}$ \\
total_skor & Sig. (2-tailed) & .000 \\
& $\mathrm{~N}$ & 100
\end{tabular}

\section{Correlations}

Sumber: Data primer yang diolah. 2016

\begin{tabular}{|c|c|c|c|}
\hline $\begin{array}{l}\text { item_ } 2 \\
.614^{\star \star}\end{array}$ & $\begin{array}{l}\text { item_3 } \\
.181\end{array}$ & $\begin{array}{l}\text { item } 4 \\
.238^{{ }^{*}}\end{array}$ & $\begin{array}{l}\text { total skor } \\
.704^{* \pi}\end{array}$ \\
\hline .000 & .072 & .017 & .000 \\
\hline $\begin{array}{l}100 \\
1\end{array}$ & $\begin{array}{l}100 \\
.396 \\
.000\end{array}$ & $\begin{array}{l}100 \\
.264^{\star *} \\
.008\end{array}$ & $\begin{array}{l}100 \\
.776 \\
.000\end{array}$ \\
\hline $\begin{array}{l}100 \\
.396\end{array}$ & $\begin{array}{l}100 \\
1\end{array}$ & $\begin{array}{l}100 \\
.428^{\star *}\end{array}$ & $\begin{array}{l}100 \\
.687^{* *}\end{array}$ \\
\hline $\begin{array}{l}.000 \\
100 \\
264^{* *}\end{array}$ & $\begin{array}{l}100 \\
428^{* *}\end{array}$ & $\begin{array}{l}.000 \\
100 \\
1\end{array}$ & $\begin{array}{l}.000 \\
100^{* *} \\
.701^{* *}\end{array}$ \\
\hline .008 & .000 & & .000 \\
\hline $\begin{array}{l}100 \\
.776\end{array}$ & $\begin{array}{l}100 \\
.687^{\text {** }}\end{array}$ & $\begin{array}{l}100 \\
.701^{\star \star}\end{array}$ & $\begin{array}{l}100 \\
1\end{array}$ \\
\hline .000 & .000 & .000 & \\
\hline 100 & 100 & 100 & 100 \\
\hline
\end{tabular}

Dari tabel 4.9 di atas tampak bahwa nilai $r$ hitung item $1=0,704$, item $2=0,776$, item $3=0,687$, item $4=0,701$, sedangkan nilai $\mathrm{r}$ tabel adalah 0,1966. Maka dapat di simpulkan bahwa semua data valid karna nilai $r$ hitung lebih besar dari $r$ tabel. 
Tabel 4.10 Hasil Uji Validitas X4

\section{Correlations}

\begin{tabular}{|c|c|c|c|c|c|c|}
\hline & Pearson Correlation & \begin{tabular}{|l} 
item_1 \\
1
\end{tabular} & $\begin{array}{l}\text { item_2 } \\
.083\end{array}$ & $\begin{array}{l}\text { item } 3 \\
.442^{* *}\end{array}$ & $\begin{array}{l}\operatorname{item}_{* *} 4 \\
.521^{*}\end{array}$ & $\begin{array}{l}\text { total skor } \\
.739^{* *}\end{array}$ \\
\hline 'item_1 & Sig. (2-tailed) & & .414 & $\mid .000$ & .000 & .000 \\
\hline & $\begin{array}{l}\mathrm{N} \\
\text { Pearson Correlation }\end{array}$ & $\begin{array}{l}100 \\
.083\end{array}$ & $\begin{array}{l}100 \\
1\end{array}$ & 100 & \begin{tabular}{|l|}
100 \\
-.067
\end{tabular} & $\begin{array}{l}100 \\
.506\end{array}$ \\
\hline item_2 & Sig. (2-tailed) & .414 & & .028 & .509 & .000 \\
\hline & & $\begin{array}{l}100 \\
.442^{* *}\end{array}$ & $\begin{array}{l}100 \\
.220\end{array}$ & $\begin{array}{l}100 \\
1\end{array}$ & $\begin{array}{l}100 \\
.457^{* *}\end{array}$ & $\begin{array}{l}100 \\
.778 *\end{array}$ \\
\hline item_3 & Sig. (2-tailed) & .000 & .028 & & .000 & .000 \\
\hline & & $\begin{array}{l}100 \\
.521^{* *}\end{array}$ & & $\begin{array}{l}100 \\
.457^{* *}\end{array}$ & $\begin{array}{l}100 \\
1\end{array}$ & $\begin{array}{l}100 \\
.676 *\end{array}$ \\
\hline item_4 & Sig. (2-tailed) & .000 & .509 & .000 & & .000 \\
\hline & $\begin{array}{l}\mathrm{N} \\
\text { Pearson Correlation }\end{array}$ & $\begin{array}{l}100 \\
.739^{* *}\end{array}$ & $\begin{array}{l}100 \\
.506\end{array}$ & $100 *$ & $\begin{array}{l}100 \\
.676\end{array}$ & $\begin{array}{l}100 \\
1\end{array}$ \\
\hline 'total_skor & Sig. (2-tailed) & .000 & .000 & .000 & .000 & \\
\hline & $\mathrm{N}$ & 100 & 100 & 100 & 100 & 100 \\
\hline
\end{tabular}

Sumber: Data primer yang diolah. 2016

Dari tabel 4.10 di atas tampak bahwa nilai $\mathrm{r}$ hitung item $1=0,739$, item $2=0,506$, item $3=0,778$, item $4=0,676$, sedangkan nilai $r$ tabel adalah 0,1966. Maka dapat di simpulkan bahwa semua data valid karna nilai $r$ hitung lebih besar dari $r$ tabel.

Tabel 4.11 Hasil Uji Validitas X5

\section{Correlations}

\begin{tabular}{|c|c|c|c|c|c|c|}
\hline & Pearson Correlation & $\begin{array}{l}\text { item_1 } \\
1\end{array}$ & $\begin{array}{l}\text { item_2 } \\
.524^{\star \star}\end{array}$ & $\begin{array}{l}\text { item_3 } \\
.525^{\star *}\end{array}$ & $\begin{array}{l}\text { item_4 } \\
.575^{\star \star}\end{array}$ & $\begin{array}{l}\text { total_skor } \\
.735^{\star \star}\end{array}$ \\
\hline item_1 & Sig. (2-tailed) & & .000 & .000 & .000 & .000 \\
\hline " & $\mathrm{N}$ & 100 & 100 & 100 & 100 & 100 \\
\hline & Pearson Correlation & $.524^{* *}$ & 1 & $.625^{* *}$ & $.493^{* *}$ & $.739^{* *}$ \\
\hline item_2 & Sig. (2-tailed) & .000 & & .000 & .000 & .000 \\
\hline & $\mathrm{N}$ & 100 & 100 & 100 & 100 & 100 \\
\hline & Pearson Correlation & $.525^{* *}$ & $.625^{* *}$ & 1 & $.629^{* *}$ & $.848^{* *}$ \\
\hline item_3 & Sig. (2-tailed) & .000 & .000 & & .000 & .000 \\
\hline & $\mathrm{N}$ & 100 & 100 & 100 & 100 & 100 \\
\hline & Pearson Correlation & $.575^{\star *}$ & $.493^{* *}$ & $.629^{* *}$ & 1 & $.846^{* *}$ \\
\hline item_4 & Sig. (2-tailed) & .000 & .000 & .000 & & .000 \\
\hline & $\mathrm{N}$ & 100 & 100 & 100 & 100 & 100 \\
\hline & Pearson Correlation & $.735^{* *}$ & $.739^{* *}$ & $.848^{* *}$ & $.846^{* *}$ & 1 \\
\hline total_skor & Sig. (2-tailed) & .000 & .000 & .000 & .000 & \\
\hline 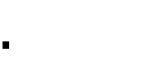 & N & 100 & 100 & 100 & 100 & 100 \\
\hline
\end{tabular}

Sumber: Data primer yang diolah. 2016 
Dari tabel 4.11 di atas tampak bahwa nilai $\mathrm{r}$ hitung item $1=0,735$, item $2=0,739$, item $3=0,848$, item $4=0,846$, sedangkan nilai $\mathrm{r}$ tabel adalah 0,1966. Maka dapat di simpulkan bahwa semua data valid karna nilai $r$ hitung lebih besar dari $r$ tabel.

Tabel 4.12Hasil Uji Validitas Y

\begin{tabular}{|c|c|c|c|c|c|}
\hline \multicolumn{6}{|c|}{ Correlations } \\
\hline \multirow{3}{*}{ item_1 } & Pearson Correlation & $\begin{array}{l}\text { item_1 } \\
1\end{array}$ & $\begin{array}{l}\text { item } 2 \\
.337^{* *}\end{array}$ & $\begin{array}{l}\text { item_3 } \\
.180\end{array}$ & $\begin{array}{l}\text { total skor } \\
.761^{* \star}\end{array}$ \\
\hline & Sig. (2-tailed) & & .001 & .072 & .000 \\
\hline & $\begin{array}{l}\mathrm{N} \\
\text { Pearson Correlation }\end{array}$ & $\begin{array}{l}100 \\
.337^{* *}\end{array}$ & $\begin{array}{l}100 \\
1\end{array}$ & $\begin{array}{l}100 \\
.091\end{array}$ & $\begin{array}{l}100 \\
.688^{* *}\end{array}$ \\
\hline \multirow[t]{2}{*}{ item_2 } & Sig. (2-tailed) & .001 & & .369 & .000 \\
\hline & $\begin{array}{l}\mathrm{N} \\
\text { Pearson Correlation }\end{array}$ & $\begin{array}{l}100 \\
.180\end{array}$ & $\begin{array}{l}100 \\
.091\end{array}$ & $\begin{array}{l}100 \\
1\end{array}$ & $\begin{array}{l}100 \\
.603^{* *}\end{array}$ \\
\hline \multirow[t]{2}{*}{ item_3 } & Sig. (2-tailed) & .072 & .369 & & .000 \\
\hline & $\begin{array}{l}\mathrm{N} \\
\text { Pearson Correlation }\end{array}$ & $\begin{array}{l}100 \\
.761^{* *}\end{array}$ & $\begin{array}{l}100 \\
.688^{* *}\end{array}$ & $\begin{array}{l}100 \\
.603^{* *}\end{array}$ & $\begin{array}{l}100 \\
1\end{array}$ \\
\hline total_skor & Sig. (2-tailed) & .000 & .000 & .000 & \\
\hline & $\mathrm{N}$ & 100 & 100 & 100 & 100 \\
\hline
\end{tabular}

Dari tabel 4.12 di atas tampak bahwa nilai $\mathrm{r}$ hitung item $1=0,761$, item $2=0,688$, item $3=0,603$, sedangkan nilai $r$ tabel adalah 0,1966. Maka dapat di simpulkan bahwa semua data valid karna nilai $r$ hitung lebih besar dari $r$ tabel.

b. Uji Reabilitas

Tabel 4.13 Hasil Uji Reabilitas

\section{Item-Total Statistics}

\begin{tabular}{|l|l|l|l|l|l|}
\hline & $\begin{array}{l}\text { Scale Mean } \\
\text { Item Deleted }\end{array}$ & if & $\begin{array}{l}\text { Scale Variance } \\
\text { if Item Deleted }\end{array}$ & $\begin{array}{l}\text { Corrected } \\
\text { Total } \\
\text { Correlation }\end{array}$ & $\begin{array}{l}\text { Cronbach's } \\
\text { Alpha if Item } \\
\text { Deleted } \\
\text { item_1 }\end{array}$ \\
76.34 & 31.964 & .167 & .801 \\
item_2 & 76.46 & 31.645 & .274 & .792 \\
item_3 & 76.50 & 31.222 & .303 & .791 \\
item_4 & 76.18 & 30.917 & .422 & .784 \\
item_5 & 76.03 & 32.211 & .260 & .792 \\
item_6 & 76.14 & 30.970 & .420 & .784 \\
item_7 & 76.06 & 30.158 & .462 & .781 \\
item_8 & 76.33 & 30.870 & .353 & .788 \\
item_9 & 76.27 & 31.088 & .354 & .788 \\
item_10 & 76.38 & 30.723 & .411 & .784 \\
item_11 & 76.51 & 31.242 & .257 & .795 \\
item_12 & 76.29 & 30.107 & .474 & .780 \\
item_13 & 76.75 & 32.169 & .136 & .803 \\
item_14 & 76.27 & 30.058 & .467 & .781 \\
item_15 & 76.19 & 30.681 & .406 & .785 \\
item_16 & 75.97 & 31.767 & .319 & .790 \\
item_17 & 76.10 & 31.384 & .333 & .789 \\
item_18 & 76.15 & 29.503 & .503 & .778 \\
item_19 & 76.09 & 30.487 & .440 & .783 \\
item_20 & 76.12 & 29.602 & .514 & .777 \\
\hline
\end{tabular}


Dari tabel di atas, di ketahui bahwa nilai Alpha sebesar 0,796, sedangkan nilai $r$ tabel adalah sebesar 0,1966. Jadi kesimpulannya adalah data tersebut reliable atau terpercaya karna nilai Alpha lebih besar dari nilai $r$ tabel.

\section{Uji Multikolonieritas}

Tabel 4.14 Hasil Uji Multokolinieritas

Coefficients $^{\mathrm{a}}$

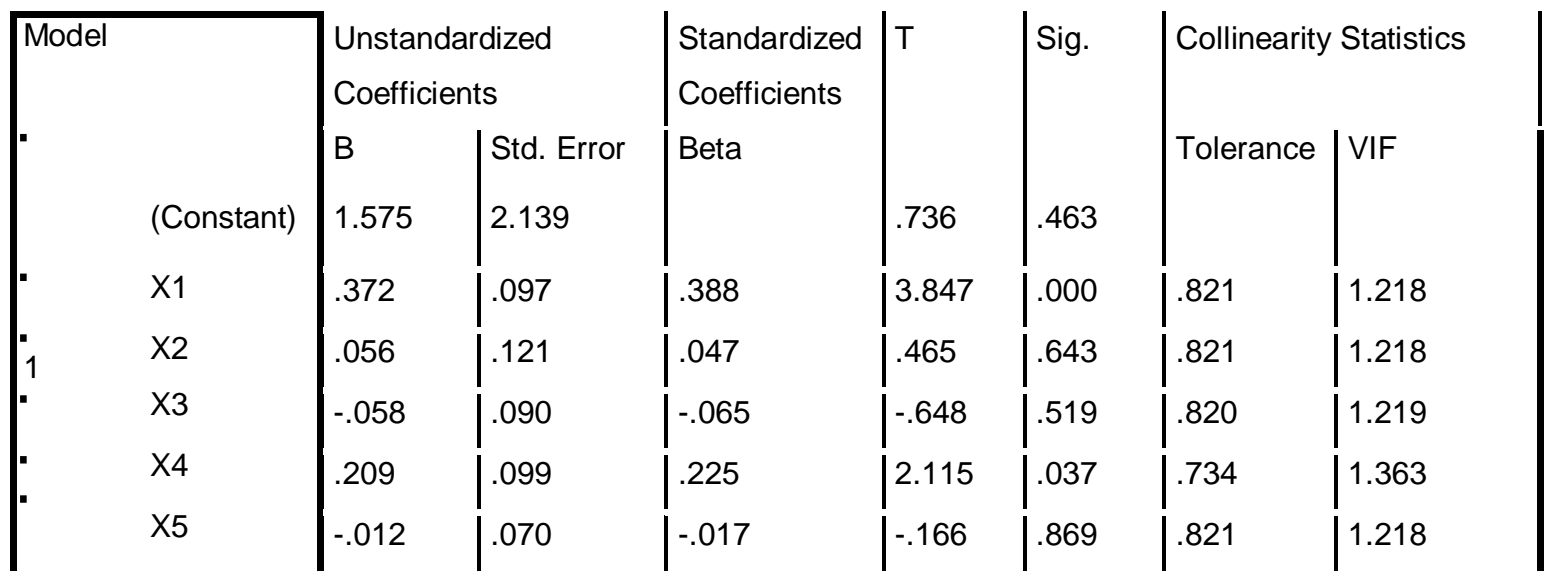

Dari tabel 4.14 di atas tampak bahwa nilai tolerance variabel bebas tidak ada yang kurang dari 0,10 . Sehingga dapat disimpulkan bahwa tidak ada multikolinieritas atara variabel bebas dalam model regresi.

\section{Uji Heteroskedatisitas}

Tabel 4.15 Hasil Uji heteroskedatisitas

Coefficients $^{\mathrm{a}}$

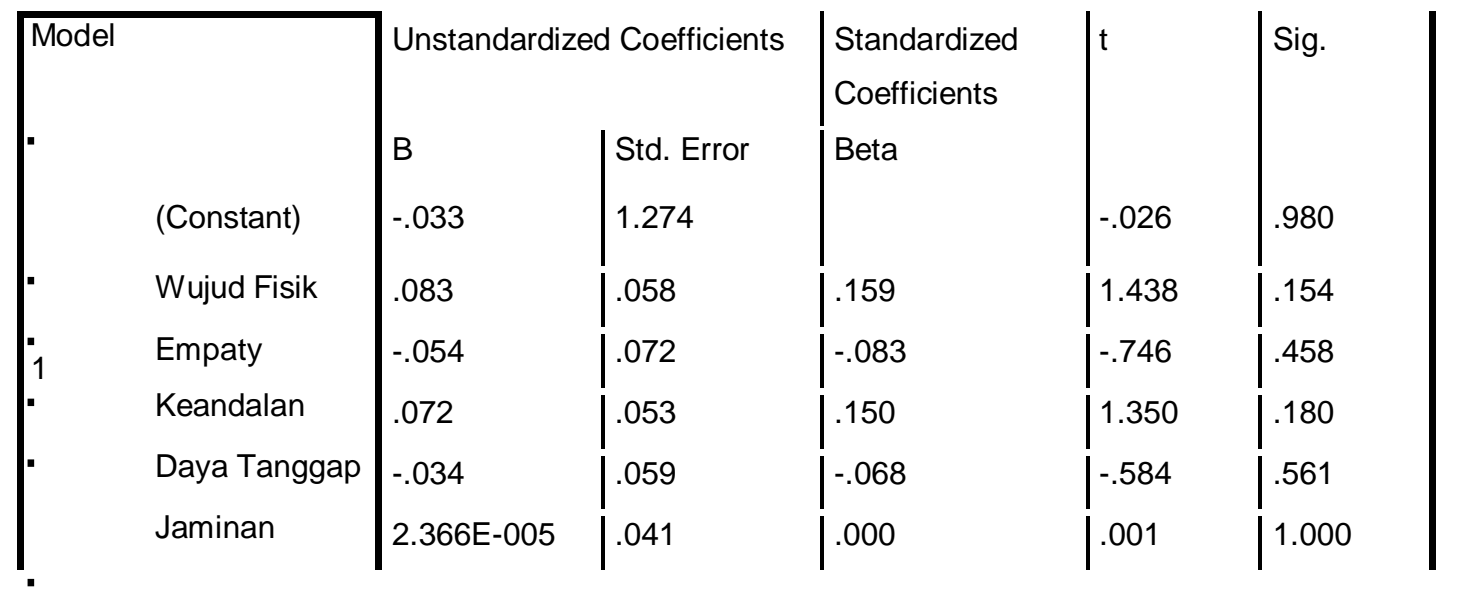

Dari tabel 4.15 di atas tampak bahwa nilai signifikasi variabel Wujud Fisik (X1) sebesar 0,154 lebih besar dari 0,05, artinya tidak terjadi heteroskedatisitas pada variabel Wujud Fisik (X1). Diketahui nilai signifikasi variabel Empaty (X2) sebesar 0,458 lebih besar 
dari 0,05, artinya tidak terjadi heteroskedatisitas pada variabel Empaty (X2). Diketahui nilai signifikasi variabel Keandalan (X3) sebesar 0,180 lebih besar dari 0,05, artinya tidak terjadi heteroskedatisitas pada variabel Keandalan (X3). Diketahui nilai signifikasi variabel Daya Tanggap (X4) sebesar 0,561 lebih besar dari 0,05, artinya tidak terjadi heteroskedatisitas pada variabel Daya Tanggap (X4). Dan diketahui nilai signifikasi variabel Jaminan (X5) sebesar 1,000 lebih besar dari 0,05, artinya tidak terjadi heteroskedatisitas pada variabel Jaminan (X5).

\section{Uji Autokorelasi}

Tabel 4.17 Hasil Uji Autokorelasi Durbin Watso

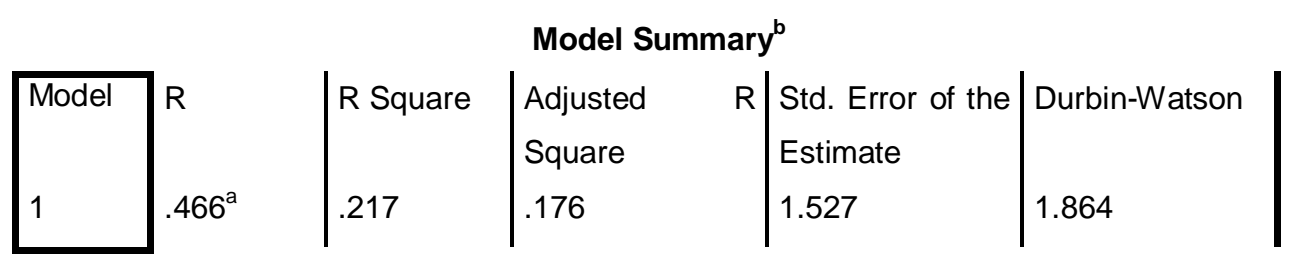

Dari tabel 4.20 diatas dapat dijelaskan bahwa nilai DW adalah 1.864, berdasarkan ketentuan Durbin Watson, maka dapat disimpulkan tidak ada autokorelasi.

\section{Uji Hipotesis}

Tabel 4.18 Hasil Output Uji t

Coefficients $^{\mathrm{a}}$

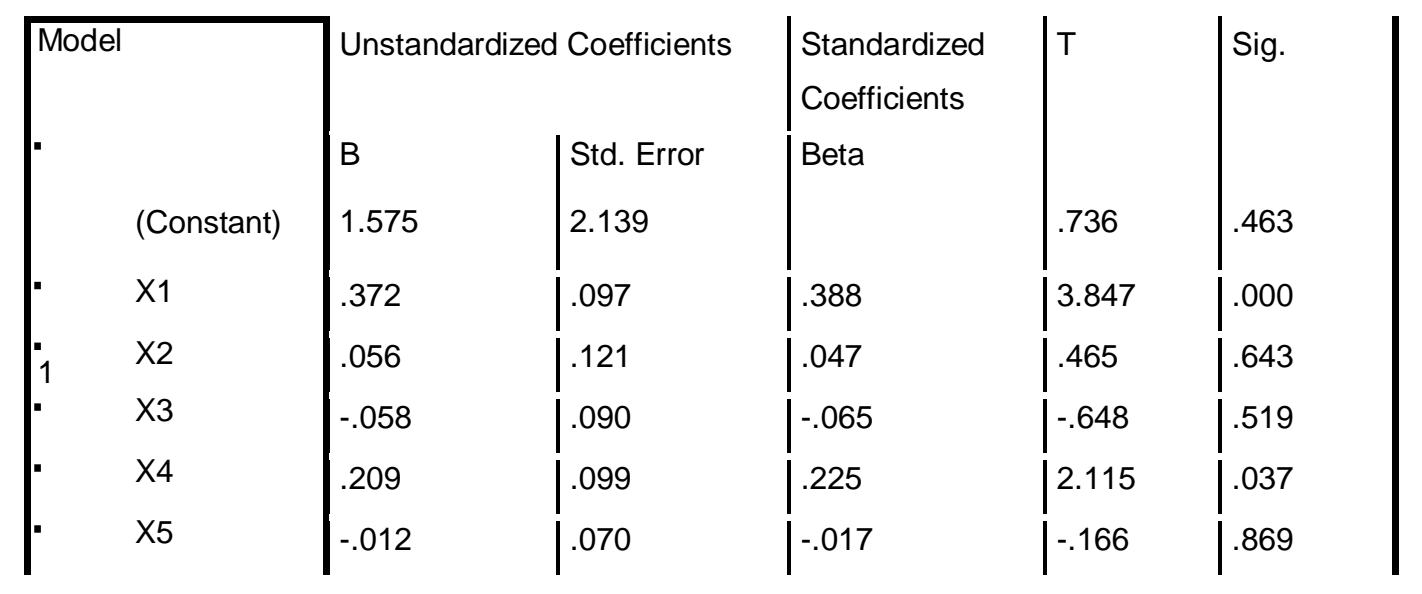

Dari hasil output di atas Nampak bahwa nilai t hitung dari variabel bebas adalah sebagai berikut:

1. Variabel $\mathrm{X} 1$ (wujud fisik) 3,847>t tabel 2,627 yang berarti bahwa variabel $\mathrm{X} 1$ mempunyai pengaruh yang signifikan terhadap variabel Y (Loyalitas Nasabah).

2. Variabel X2 (Empaty) 0,465 < t tabel 2,627 yang berarti bahwa variabel $\mathrm{X} 2$ tidak mempunyai pengaruh yang signifikan terhadap variabel Y (Loyalitas Nasabah) 
3. Variabel X3 (Keandalan) 0,648 < t tabel 2,627 yang berarti bahwa variabel $\mathrm{X} 3$ tidak mempunyai pengaruh yang signifikan terhadap variabel Y (Loyalitas Nasabah)

4. Variabel X4 (Daya Tanggap) 2,155 < t tabel 2,627 yang berarti bahwa variabel X4 tidak mempunyai pengaruh yang signifikan terhadap variabel Y (Loyalitas Nasabah)

5. Variabel X5 (Jaminan) 0,166 < t tabel 2,627 yang berarti bahwa variabel X5 tidak mempunyai pengaruh yang signifikan terhadap variabel Y (Loyalitas Nasabah)

a. Uji F digunakan untuk mengetahui apakah variabel-variabel bebas secara simultas yang berpengaruh terhadap variabel terikat.

Tabel 4.19. Hasil Output Uji F

ANOVA $^{\text {a }}$

\begin{tabular}{|ll|l|l|l|l|l|}
\hline Model & & Sum of Squares & $\mathrm{df}$ & Mean Square & $\mathrm{F}$ & Sig. \\
& Regression & 60.818 & 5 & 12.164 & 5.217 & $.000^{\mathrm{b}}$ \\
\hline 1 & Residual & 219.182 & 94 & 2.332 & & \\
& Total & 280.000 & 99 & & &
\end{tabular}

Dari hasil output di atas nampak bahwa nilai $\mathrm{F}$ hitung 5,217 > F tabel 1,93 maka variabel X1,X2,X3,X4 dan X5 secara simultan berpengaruh signifikan terhadap variabel Y.

\section{Uji Regresi Linier Berganda}

Analisis regresi linier berganda terdiri dari beberapa variabel bebas ( wujud fisik, empati, keandalan, daya tanggap dan jaminan) dan satu variabel terikat (loyalitas nasabah), dengan persamaan :

$$
Y=a+x 1 b 1+x 2 b 2+x 3 b 3+x 4 b 4+x 5 b 5+e
$$

Tabel 4.20. Uji Regresi Linier Berganda

\section{Coefficients $^{\mathrm{a}}$}

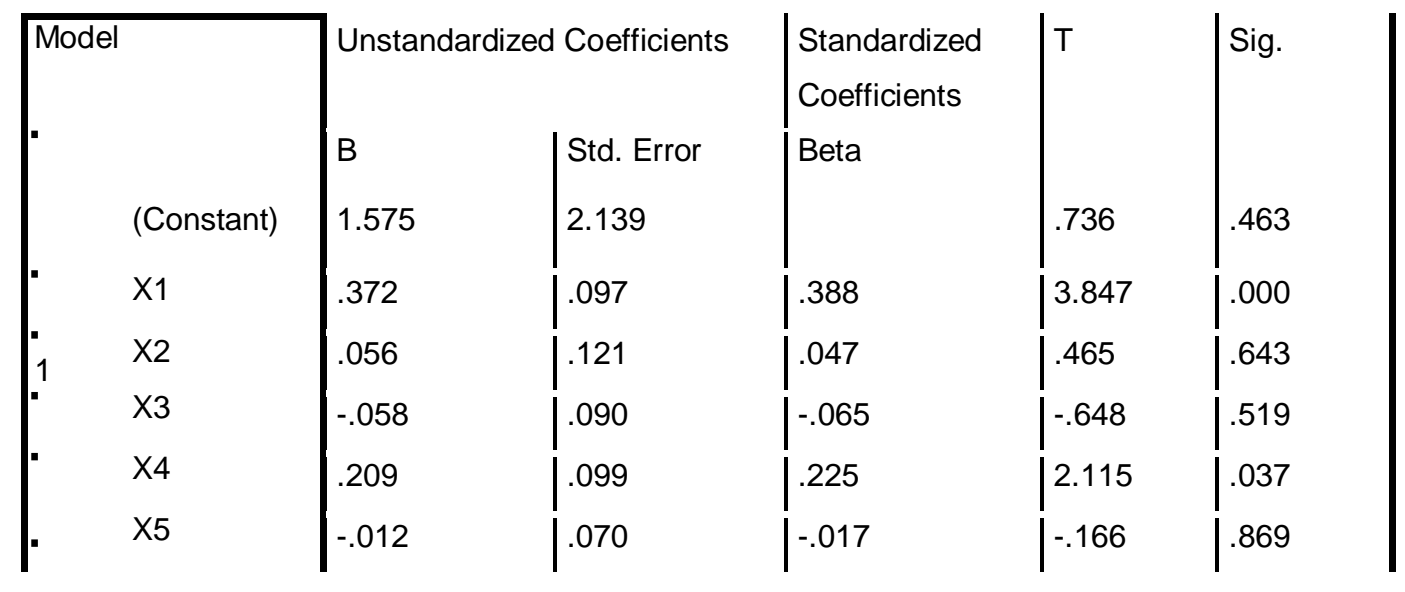


Pada tabel 4.20 Coefficients, pada kolom B pada Constant (a) adalah 1.575, sedangkan nilai variabel wujud fisik 0,372, empati 0,056, keandalan -.058, daya tanggap 0,209 dan jaminan -.012 sehingga persamaan regresi dapat di tulis:

$$
\mathrm{Y}=1.575+0,372+0,056+-.058+0,209+-.012 \mathrm{X}
$$

\section{KESIMPULAN}

Dari hasil penelitian dan pengolahan data dapat disimpulkan bahwa:

1. Variabel bebas X1 (Wujud fisik) berpengaruh secara signifikan terhadap variabel Y (Loyalitas Nasabah) sedangkan empat variabel bebas lainnya yaitu X2 (Empaty), X3 (Keandalan), X4 (Daya Tanggap), X5 (Jaminan) tidak berpengaruh secara signifikan terhadap variable $\mathrm{Y}$ (Loyalitas Nasabah), ini dibuktikan dengan menggunakan uji $\mathrm{t}$ dimana variabel wujud fisik mempunyai t hitung 3,847 lebih besar dari nilai t tabel 2,627, sedangkan keempat variabel tersebut mempunyai t hitung empati 0,465 , keandalan 0,648 , daya tanggap 2,155, dan jaminan 0,166 tidak lebih besar dari nilai t tabel 2,627.

2. Sedangkan secara simultan variabel bebas, X1 (Wujud Fisik), X2 (Empaty), X3 (Keandalan), X4 (Daya Tanggap) dan X5 (Jaminan) berpengaruh secara signifikan terhadap variabel terikat Y (Loyalitas Nasabah), ini dibuktikan dengan menggunakan uji f dimana variabel wujud fisik, empati, keandalan, daya tanggap dan jaminan mempunyai $f$ $\begin{array}{lllllll}\text { hitung } & 5,217 & \text { lebih } & \text { besar } & \text { dari } & \mathrm{f} & \text { tabel }\end{array}$ 


\section{DAFTAR PUSTAKA}

Arikonto, Suharsimi, Prosedur Penelitian, Jakarta, PT. Rineka cipta, 1998.

Arikonto Suharsimi, Prosedur Penelitian Suatu Pendekatan Praktek, Jakarta: PT. Rieneka Cipta 2000.

Abdullah, Ruslan \& Kamal, Fasiha, Pengantar Islamic Economics, Makasar :Lumbung Informasi Pendidikan LIPa, 2013.

Bungin M. Burhan, Metodologi Penelitian Kuantitatif, Jakarta, Prenada Media, 2005

Huryati, Ratih, Bauran Pemasaran dan Loyalitas Konsumen, Bandung : Alfabeta, 2010.

Hasan, Zubairi, Undang-Undang Perbankan Syariah, Jakarta : PT. Rajagrafindo Persada, 2009.

Ismail, Perbankan Syariah, Jakarta:Kencana, 2011.

Irawan, Handi, 10 Prinsip Kepuasan Pelanggan, Jakarta :PT. Elex Media Kompotindo, 2002.

Kadir, Hasrida, "Pengaruh Pelayanan Customer Service Terhadap Loyalitas nasabah pada Bank Syariah Mandiri Cabang Kota Palopo", skripsi,STAIN Palopo 2014.

Kotler, Philip, Lane Keller, Kevin, Manajemen Pemasaran, Person Education/ PT. Indeks 2006/ 2007.

Lupiyoudi, Rambat \& Hamdani, A., Manajemen Pemaasaran Jasa, Jakarta : Salemba Empat, 2006.

Paulus Lilik, Kristianto, Psikologi Pemasaran, Yogyakarta CAPS 2011.

Sunarno, Ariyanti, Pengaruh kualitas pelayanan frontliner terhadap loyalitas nasabah pada Bank BTN Syariah Cabang Bandung, Skripsi, UI Bandung 2011.

Sumar'in, Konsep Kelembagaan Bank Syariah, Yogyakarta, Graha Ilmu, 2012.

S Nasution. Metode Research, Cet. I; Jakarta: Bumi Aksara, 2003.

Saputra, anwar Lyndon, Raving Fans Menciptakan Pelanggan Fanatik, ken Blanchard \& Sheldon bowles batam cantre, 2003.

Sugiyono, Metode Penelitian Bisnis, Bandung, Alfabet, 2008.

Sulaiman Wahid, Analisis Regresi Menggunakan SPSS Contoh Kasus dan Pemecahannya, Yogyakarta, Andi Offset, 2014.

Wijayanti, Nina, "Faktor-faktor yang mempengaruhi loyalitas nasabah PT. Bank Rakyat Indonesia TBK”, Skripsi, UIN Syarif Hidayatullah Jakarta 2010. 